\title{
Kinetic Modelling of Solid-Liquid Extraction of Anthocyanins of Gynura Crepioides Leaves
}

\author{
Wong Mei Lin ${ }^{1}$, Zurina Zainal Abidin ${ }^{1}$ * \\ ${ }^{1}$ Department of Chemical Engineering, Faculty of Engineering, Universiti Putra Malaysia (UPM), Serdang, 43400 \\ Selangor Darul Ehsan \\ *Corresponding author E-mail: zurina@upm.edu.my
}

\begin{abstract}
Gynura crepioides is one of the natural resources of flavonoid compounds, including anthocyanins (ACs) that provide a lot of nutritional values to human and use as a natural colourant. For efficient extraction, optimization and kinetic data is very essential. In this investigation, optimization and kinetic modelling focusing on temperature effect on solid-liquid extraction of freeze-dried anthocyanins leaves of Gynura crepioides was performed. Freeze drying material was used in extraction to ensure high recovery of useful bioactive compounds in subsequent process. It was found that the rate of extraction was very fast at the beginning, but it began to slow down until it remained constant and reached the plateau after 45 minutes for all temperatures. As temperature increases, the initial extraction rate (h) and extraction rate constant $(\mathrm{k})$ values also increased. The highest initial extraction rate and extraction rate constant were calculated to be $16.64 \mathrm{mg}$ $\mathrm{L}^{-1} \mathrm{~min}^{-1}$ and $17.8 \times 10^{-3} \mathrm{~L} \mathrm{mg}^{-1} \mathrm{~min}^{-1}$ at $333 \mathrm{~K}$. However, after 60 minutes of extraction time, degradation of anthocyanins can be seen at $333 \mathrm{~K}$ and thus reduce the yield. Higher temperature is known to reduce the quantity and quality of bioactive compound. Hence temperature of lower than $333 \mathrm{~K}$ is desirable for industrial application. The kinetics of extraction data were corresponding well to second-order reaction. The activation energy is calculated as $18.45 \mathrm{~kJ} \mathrm{~mol}^{-1}$, which is an indication of an endothermic process. An empirical correlation was also done to establish the relationship of extraction rate constant and initial extraction rate with respect to temperature. Both parameters were found to increase with increase temperature. Finally, a three-dimensional model was predicted to show the capacity of extraction at all times and temperatures of extraction. This predicted model exhibited good fitting to experimental values with low standard deviation.
\end{abstract}

Keywords: second-order mechanism, Gynura crepioides, solid-liquid extraction, anthocyanins

\section{Introduction}

Gynura crepioides, also known as "Hong Feng Cai" in Chinese and "Sambung Nyawa Ungu" in Malay language. It belongs to the botanical family of compositae. The major flavonoids compound found in G. crepioides includes anthocyanins, quercetin, kaempferol, quercitrin, isoquercitrin, and rutin [1]. This plant is reported to have medicinal values [2-3] and the reddish purple pigments on its leaves are believed to be anthocyanins [3]. These compounds can be extracted by efficient solid-liquid extraction method at optimum extraction parameters with suitable solvent. Most of the kinetics of anthocyanins degradation of many other plants or fruits with the influence of temperatures and $\mathrm{pH}$ of the medium had been studied [4-5], but the study of kinetic for anthocyanins extraction is not yet elucidated.

The rate of extraction is very important to be defined in design of any solid liquid extraction system. Consequently, it can be used to predict the kinetic modelling at any times and temperatures, by finding the rate constant, saturated extraction capacity, and initial extraction rate. Activation energy is also defined in order to determine the amount of energy released or used throughout the extraction process. Generally, extraction of anthocyanins from G. crepioides leaves was modeled as second-order reaction that will normally takes place with two phenomena: 1) fast dissolution; 2) and scrubbing of solute into fresh solvent by driving force, and then slower extraction process take places which correspond by external diffusion of a part of solute into the fresh solvent [6]. In this study, the mechanism and kinetic modelling of anthocyanins (ACs) extraction from G. crepioides leaves was investigated using conventional solid liquid extraction. Yield of anthocyanins was used as a basis to evaluated it performance using uvvis spectrophotometer (UV-1800) with cyanidin-3-glucoside as standard and distilled water as blank at $520 \mathrm{~nm}$. Further analysis was done to determine its kinetic modelling of the extraction process.

\section{Materials and method}

\subsection{Chemicals and raw materials}

Gynura crepioides or Sambung Nyawa Merah were purchased from MARDI in Selangor, Malaysia. Firstly, the leaves of G. crepioides were cleaned and freeze dried. After grinding, the leaves of G. crepioides were kept in a container covered with aluminium foil in a freezer at $-20^{\circ} \mathrm{C}$ for further analysis.

\subsection{Preparation of Extracts}

Freeze dried leaves of G. crepioides were extracted based on the solvent formulation at various times and temperatures by using 
conventional solid-liquid extraction. The influence of temperature on the extraction kinetics was studied while keeping all the other factors constant (solid to solivent ratio, methanol to aqueous $\mathrm{HCl}$ ratio, $\mathrm{HCl}$ concentration) and carried out at 303, 313, 323, and 333 $\mathrm{K}$ with a different time (0 to 300 minutes). The kinetics of extraction was evaluated by withdrawing extracts of $1 \mathrm{~mL}$ from the extraction medium at the various time. The absorbance value of extracts was measured by using Shimadzu UV-vis spectrophotometer (UV-1800, Kyoto, Japan) at $520 \mathrm{~nm}$ and distilled water as blank.

\subsection{Kinetic model}

A second order mechanism normally will take place with two phenomena. First, the fast dissolution and scrubbing of solute into fresh solvent by driving force, and then the slower extraction process take places which correspond by external diffusion of a part of solute into the fresh solvent [6].

Two assumptions were used in this study, which are first- and second-order reaction. All of the readings from the study were calculated based on the formulae given to the equation from firstand second-order reaction. The first order kinetic rate equation generally used for ACs at different extraction temperature and contact time, can be written as follow [6].

Rate $=\frac{\mathrm{dC}_{\mathrm{ACs}, \mathrm{t}}}{\mathrm{dt}}=\mathrm{kC}_{\mathrm{ACs}, \mathrm{t}}$

The integrated rate law for a first-order degradation model is

$\ln \mathrm{C}_{\mathrm{ACs}, \mathrm{t}}=\ln \mathrm{C}_{\mathrm{ACs}, 0}-\mathrm{kt}$

Where $\mathrm{k}$ is the rate constant $\left(\mathrm{min}^{-1}\right), C_{A C S, 0}$ is the initial concentration of ACs at 0 minutes, and $C_{A C s, t}$ is the concentration of anthocyanins in the solution at any time $\mathrm{t}(\mathrm{min})$.

Another form of first order rate law is as follows:

$\mathrm{C}_{\mathrm{ACs}, \mathrm{t}}=\mathrm{C}_{\mathrm{ACs}, 0} \mathrm{e}^{-\mathrm{kt}}$

The second order kinetic rate equation, which represents the dependence of the extraction rate on the concentration of ACs dissolved into solvent, can be written as follows:

$\frac{\mathrm{dC}_{\mathrm{ACs}, \mathrm{t}}}{\mathrm{dt}}=\mathrm{k}\left(\mathrm{C}_{\mathrm{s}}-\mathrm{C}_{\mathrm{ACs}, \mathrm{t}}\right)^{2}$

Where $\mathrm{k}$ is the second-order extraction rate constant $\left(\mathrm{L} \mathrm{mg}^{-1} \mathrm{~min}\right.$ $\left.{ }^{1}\right), C_{S}$ is the saturated extraction capacity where the concentration of anthocyanin at saturation $\left(\mathrm{mg} \mathrm{L}^{-1}\right)$, and $\mathrm{C}_{\mathrm{ACs}, \mathrm{t}}$ is the concentration of anthocyanins in the solution at any time $t(\mathrm{~min})$.

By considering initial condition $t=0$ to $t$ and $C_{A C s, t}=0$ to $C_{A C s, t}$, the integrated rate law for a second-order extraction was obtained:

$\mathrm{C}_{\mathrm{ACs}, \mathrm{t}}=\frac{\mathrm{C}_{\mathrm{s}}^{2} \mathrm{kt}}{1+\mathrm{C}_{\mathrm{s}} \mathrm{kt}}$

Linear form of the equation above:

$\frac{\mathrm{t}}{\mathrm{C}_{\mathrm{ACs}, \mathrm{t}}}=\frac{1}{\mathrm{kC}_{\mathrm{s}}^{2}}+\frac{\mathrm{t}}{\mathrm{C}_{\mathrm{s}}}$

The extraction rate can be written as following equation:

$\frac{\mathrm{C}_{\mathrm{ACs}, \mathrm{t}}}{\mathrm{t}}=\frac{1}{\left(\frac{1}{\mathrm{kC}_{\mathrm{S}}^{2}}\right)+\left(\frac{\mathrm{t}}{\mathrm{C}_{\mathrm{S}}}\right)}$

Then, by $\mathrm{t}$ approaches 0 , the initial extraction rate, $\mathrm{h}$, as $\mathrm{C}_{\mathrm{t}} / \mathrm{t}$ can be written as:
$\mathrm{h}=\mathrm{kC}_{\mathrm{s}}^{2}$

By arrangement of equation (8), the concentration of ACs at any time can be obtained as:

$\mathrm{C}_{\mathrm{ACs}, \mathrm{t}}=\frac{\mathrm{t}}{\frac{1}{\mathrm{~h}}+\frac{\mathrm{t}}{\mathrm{C}_{\mathrm{s}}}}$

Arrhenius law describes the dependence of the extraction rate constant on the temperature. The activation energy of the process can be calculated using Arrhenius equation.

$\mathrm{k}=\mathrm{A} \exp \left(-\frac{\mathrm{E}}{\mathrm{RT}}\right)$

where $\mathrm{k}$ is the second-order extraction rate constant $\left(\mathrm{L} \mathrm{mg}^{-1} \mathrm{~min}^{-1}\right)$ $\mathrm{A}$ is the temperature independent factor $\left(\mathrm{L} \mathrm{mg}^{-1} \mathrm{~min}^{-1}\right), \mathrm{E}$ is the activation energy $(\mathrm{J} / \mathrm{mol}), \mathrm{R}$ is the gas constant $(8.314 \mathrm{~J} / \mathrm{mol} \mathrm{K})$, and $\mathrm{T}$ is absolute temperature in Kelvin $(\mathrm{K})$. Activation energy is the minimum energy for the extraction of anthocyanins from $G$. crepioides leaves.

A plot of $\mathrm{k}$ versus temperature shows an exponential increasing. By rearranging the equation (11):

$\operatorname{lnk}=\ln A+\left(-\frac{E_{A}}{R T}\right)$

If $\ln \mathrm{k}$ is plotted against $1 / \mathrm{T}$, where $\mathrm{T}$ is in Kelvin, a straight line with negative slope of $E_{A} / R T$ and an intercept of ln A will be obtained. Most of the reaction obeys the Arrhenius equation and implys that either $\mathrm{A}$ or $\mathrm{E}_{\mathrm{A}}$ or both are varying with temperature [8] All of these calculations on first- and second- reaction had been calculated by using Microsoft Excel and the 3-D plot of modelling for solid-liquid extraction of ACs from G. crepioides leaves at any time and temperature developed by using Matlab.

\section{Result and discussion}

The kinetics of solid-liquid extraction of ACs from G.crepioides was reported in this study. The experiments were carried out using the formulation of the solvent. As in Figure 1, the rate of extraction was very fast at the beginning, but it began to slow down until it remained constant and reached the plateau after 45 minutes for all temperatures. The initial rapid extraction rate is achieved mainly through the molecular diffusion of ACs into the solvent of acidified methanol. While applying the heat along with time, the denaturation of the cell wall of the G. crepioides leaves increased the solubility of ACs into acidified methanol until it reached the equilibrium. These observations can be seen at Figure 2 .

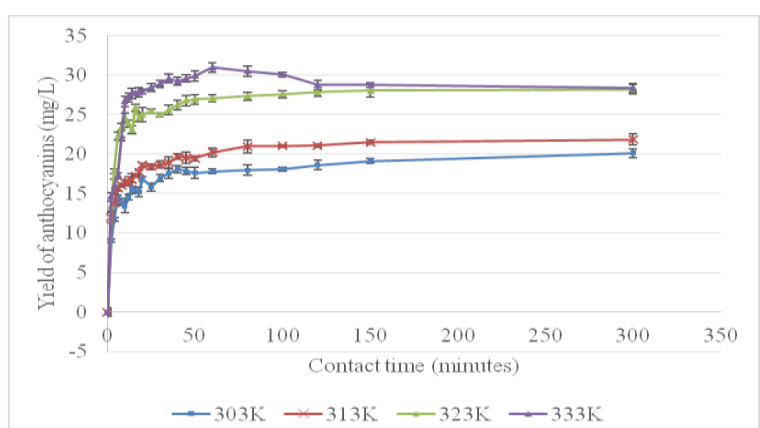

Figure 1: Yield of extracted anthocyanins versus time at different temperatures in the solid-liquid extraction of $G$. crepioides leaves using the formulation of solvent for 300 minutes.

In order to determine the reaction order for the anthocyanins extraction, both graphs of $\mathrm{Ln}\left(\mathrm{c} / \mathrm{c}_{0}\right)$ and $\mathrm{t} /\left[\mathrm{c}_{\mathrm{t}}\right]$ against time for firstand second-order reaction were plotted respectively. The kinetic extraction of anthocyanins did not follow the first-order as the ACs content versus time was not linear as shown at Figure 2. 


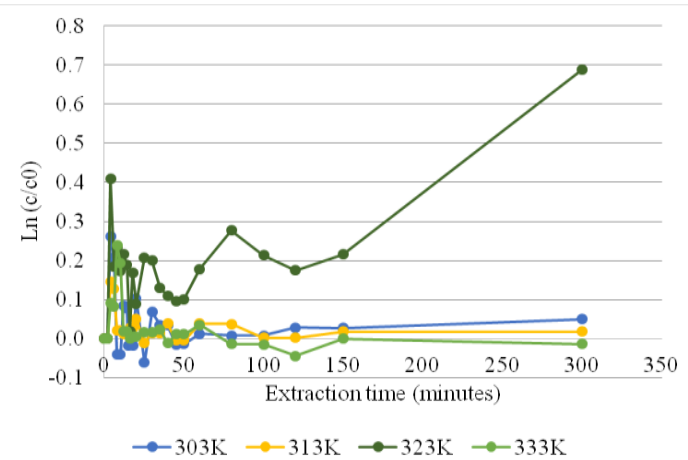

Figure 2: First-order kinetics extraction of anthocyanins at different temperatures using the formulation of solvent for 300 minutes.

On the other hand, Figure 3 showed a linear straight line curve with positive slope and high values of $R^{2}$ (Table 1 ) in the series of plots $t /\left[c_{t}\right]$ against time at different temperature. The straight-line curve as shown in Figure 3 proved that the experimental results conformed well to the second-order reaction. This confirmed that the extraction of ACs from the G. crepioides leaves took place in two stages: the first initial stage of extraction is where the maximum extraction takes place due to the high dissolution and scrubbing, then followed by a slower stage at which the external diffusion of the remainder solute into solution [6].

The saturated extraction capacity, $\mathrm{C}_{\mathrm{s}}$, extraction rate constant, $\mathrm{k}$, the initial extraction rate, $\mathrm{h}$, and the coefficient of determination, $\mathrm{R}^{2}$ determined from the equation (8) by obtaining the linear line with positive slope (Figure 3 ) are shown in Table 1.

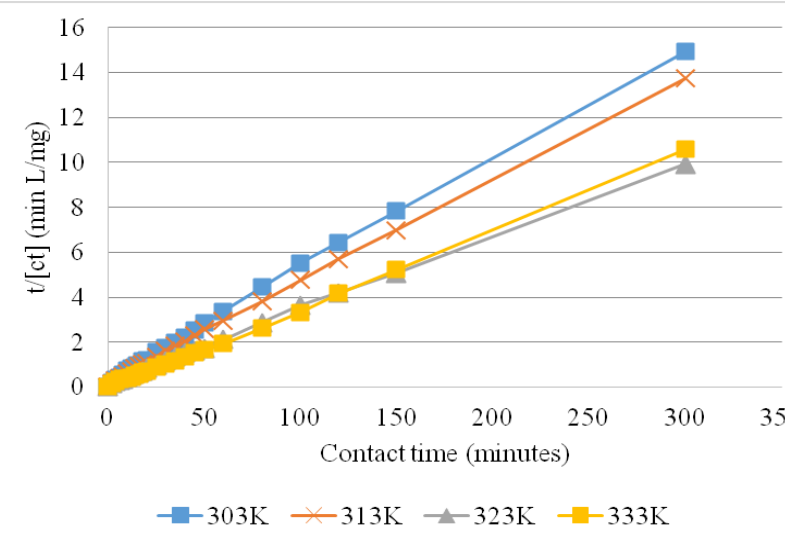

Figure 3: Second-order kinetics extraction of anthocyanins at various temperatures and times using the formulation of solvent.

Table 1: Linearization of the kinetic model of the second-order mechanism solid-liquid extraction at various temperatures of G. crepioides leaves.

\begin{tabular}{|c|c|c|c|c|c|}
\hline \multirow{2}{*}{$\begin{array}{c}\text { Temperature } \\
\text { (K) }\end{array}$} & \multirow{2}{*}{$\begin{array}{l}\text { Model } \\
\text { equation }\end{array}$} & \multicolumn{3}{|c|}{ Model parameter } & \multirow[t]{2}{*}{$\mathrm{R}^{2}$} \\
\hline & & $\begin{array}{c}\mathrm{Cs} \\
\left(\mathrm{mg} \mathrm{L}_{1} \mathrm{~L}^{-}\right.\end{array}$ & $\begin{array}{l}\mathrm{h}\left(\mathrm{mg} \mathrm{L}^{-}\right. \\
\left.{ }^{1} \min ^{-1}\right)\end{array}$ & $\begin{array}{c}\mathrm{k}\left(\mathrm{L} \mathrm{mg}{ }^{-1}\right. \\
\left.\min ^{-1}\right)\end{array}$ & \\
\hline 303 & $\begin{array}{c}\mathrm{t} /\left[\mathrm{c}_{\mathrm{t}}\right]=0.05 \mathrm{t}+ \\
0.25\end{array}$ & 20.00 & 4.06 & $10.2 \times 10^{-}$ & 0.9983 \\
\hline 313 & $\begin{array}{c}\mathrm{t} /\left[\mathrm{c}_{\mathrm{t}}\right]=0.05 \mathrm{t}+ \\
0.18\end{array}$ & 21.98 & 5.52 & $11.4 \times 10^{-}$ & 0.9995 \\
\hline 323 & $\begin{array}{c}\mathrm{t} /\left[\mathrm{c}_{\mathrm{t}}\right]=0.04 \mathrm{t}+ \\
0.09\end{array}$ & 28.41 & 11.51 & $14.3 \times 10^{-}$ & 0.9998 \\
\hline 333 & $\begin{array}{c}\mathrm{t} /\left[\mathrm{c}_{\mathrm{t}}\right]=0.03 \mathrm{t}+ \\
0.06\end{array}$ & 30.58 & 16.64 & $17.8 \times 10^{-}$ & 0.9998 \\
\hline
\end{tabular}

The $\mathrm{C}_{\mathrm{s}}$ increases from 20.00 to $30.58 \mathrm{mg} \mathrm{L}^{-1}$, with the temperature changing from $303 \mathrm{~K}$ to $333 \mathrm{~K}$. The value of $\mathrm{k}$ and $\mathrm{h}$ also increased with temperatures from $10.2 \times 10^{-3}$ to $17.8 \times 10^{-3} \mathrm{~L} \mathrm{mg}^{-1} \mathrm{~min}^{-1}$ and 4.06 to $16.64 \mathrm{mg} \mathrm{L}^{-1} \mathrm{~min}^{-1}$ respectively. Based on Table 4.2 , the highest values of $\mathrm{C}_{\mathrm{s}} \mathrm{h}$ and $\mathrm{k}$ were $30.58 \mathrm{mg} \mathrm{L}^{-1}, 16.64 \mathrm{mg} \mathrm{L}^{-1} \mathrm{~min}^{-}$ ${ }^{1}$, and $17.8 \times 10^{-3} \mathrm{~L} \mathrm{mg}^{-1} \mathrm{~min}^{-1}$, respectively at $333 \mathrm{~K}$. Accordingly, high value of $\mathrm{k}, 17.8 \times 10^{-3} \mathrm{~L} \mathrm{mg}^{-1} \mathrm{~min}^{-1}$ represents fast reaction in extraction process at $333 \mathrm{~K}$. On the other hand, for temperature $333 \mathrm{~K}$ after 60 minutes of extraction time the yield of ACs started to decline in amount that suggested degradation of ACs has taken place at that temperature (Figure 1). Unlike at other lower temperature below $333 \mathrm{~K}$, this behaviour is not apparent. This means lower temperature is better for extraction this thermoliable product and able to maintain the quality of ACs from degradation. This is thus more desirable at industrial scale in order to assure the quality and quantity of ACs.

In comparison to the study by Tzima et al. (2014) [7], the extraction of total flavonoids from red grape pomace at various temperatures $\left(30,40\right.$ and $\left.60^{\circ} \mathrm{C}\right)$ over a period of 320 minutes conformed to the second-order mechanism. The $\mathrm{k}, \mathrm{h}$, and yield of total flavonoids $\left(\mathrm{Y}_{\mathrm{TFn}(\mathrm{s})}\right)$ or $\mathrm{C}_{\mathrm{s}}$ values were determined in this reaction as well. At $40^{\circ} \mathrm{C}$ high reaction rate was observed as the $\mathrm{k}$ value $\left(1.675 \mathrm{x} 10^{-}\right.$ ${ }^{4} \mathrm{~L} \mathrm{mg}^{-1}$ min- $^{1}$ ) was greater in comparison to 30 and $60^{\circ} \mathrm{C}$. This result suggested that, less flavonoid will be extracted at a temperature above $40^{\circ} \mathrm{C}$, where the $\mathrm{Y}_{\mathrm{TFn}(\mathrm{s})}$ at $60^{\circ} \mathrm{C}$ is less than $40^{\circ} \mathrm{C}$. Thus, the temperature for extraction cannot exceed $40^{\circ} \mathrm{C}$ in order to achieve high $\mathrm{Y}_{\mathrm{TFn}(\mathrm{s})}$ in this case [7].

By comparison, the $\mathrm{k}$ value in the extraction of ACs from $G$. crepioides at $40^{\circ} \mathrm{C}$ or $313 \mathrm{~K}\left(0.0114 \mathrm{~L} \mathrm{mg}^{-1} \mathrm{~min}^{-1}\right)$ is higher than $\mathrm{k}$ value in the extraction of flavonoid from Red Grape Pomace [7] at $40^{\circ} \mathrm{C}\left(1.675 \times 10^{-4} \mathrm{~L} \mathrm{mg}^{-1} \mathrm{~min}^{-1}\right)$ showing a faster rate of reaction of ACs from the leaves of G. crepioides. From this point of view, the comparison of rate constants presents the best method to verify the rate of extraction of studied natural products from plants. These rate constants are directly related to the extraction so that a higher rate constant corresponds to a better extraction rate of extracts. In addition, the reason for this discrepancy may be due to the types and properties of targeted compounds to be extracted and the suitability of targeted compounds to be extracted at certain temperatures or conditions.

In addition, the increasing of $\mathrm{k}$ with temperatures can be proven using Arrhenius equation (12). By plotting the $\ln (\mathrm{k})$ against 1/T as shown at Figure 4 based on the equation (13) to calculate the values of $\mathrm{Ea}$ and $\mathrm{A}$, where $\ln \mathrm{A}$ is the intercept and $-\mathrm{E} / \mathrm{R}$ is the slope of linear plot $\ln (\mathrm{k})$ versus $1 / \mathrm{T}$. there was a linear relationship between the $\ln (\mathrm{k})$ and $1 / \mathrm{T}$ with linear equation of $" y=-2219 x+2.1425 "$ and a high value of $R^{2}(0.9722)$.

$\mathrm{k}=8.52 \exp \left(\frac{-18.45}{8.314 \mathrm{~T}}\right)$

From equation (14), the constant, $\mathrm{A}$, is $8.52 \mathrm{~L} \mathrm{mg}^{-1} \mathrm{~min}^{-1}$, while the activation energy, the minimum energy for solid-liquid extraction of ACs from the freeze dried of $G$. crepioides leaves, $\mathrm{E}_{\mathrm{a}}$, is $18.45 \mathrm{~kJ} \mathrm{~mol}^{-1}$. The positive value of $\mathrm{E}_{\mathrm{a}}$ shows that the solid-liquid extraction of ACs from the leaves of G. crepioides is an endothermic process as well.

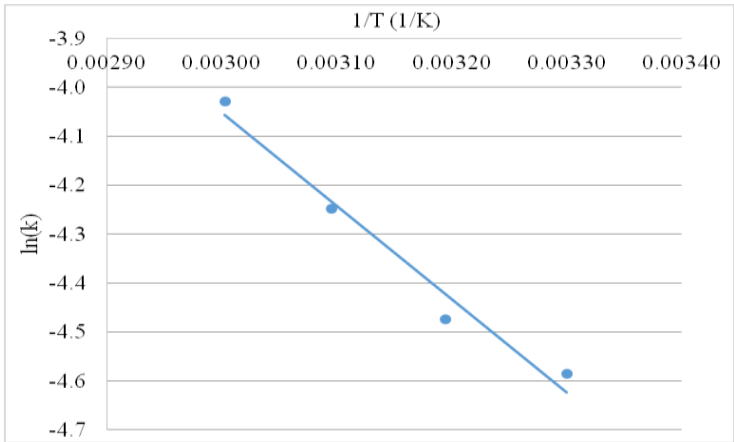

Figure 4: Relationship between temperature and the second-order mechanism rate constant, $\ln (\mathrm{k})$, for solid-liquid extraction of G.crepioides leaves.

Further empirical analysis was done to establish the relationship of $\mathrm{h}$ with temperature. Figure 5 shows that $\mathrm{h}$ increased with the extraction temperature. A linear relationship between $\ln (\mathrm{h})$ and $\mathrm{T}$ 
with high $\mathrm{R}^{2}$ (0.9846) was observed and it is shown in Figure 6. Values of $\mathrm{h}$ can be correlated by an empirical equation that can be described as follows:

$\mathrm{h}=0.0088 \mathrm{~T}^{2}-5.6226 \mathrm{t}+898.3$

In addition, the saturation extraction capacity Cs behaviour with respect to temperature was also empirically correlated and the following relationship was obtained:

$\mathrm{C}_{\mathrm{s}}=0.014 \mathrm{~T}^{2}-9.3013 \mathrm{~T}+1561.1$

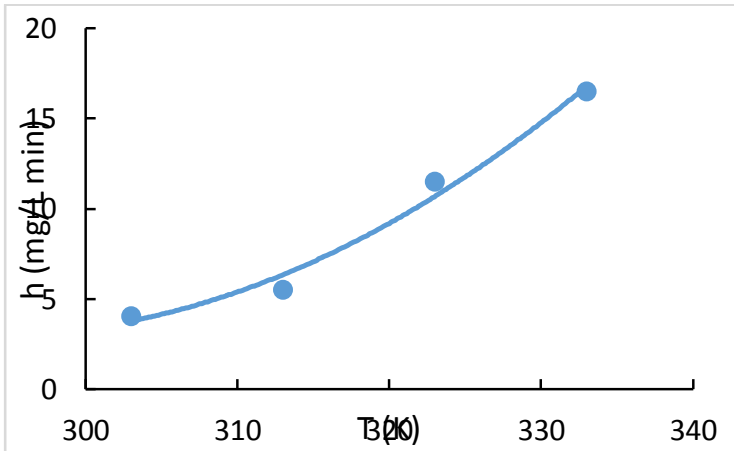

Figure 5: Relationship between the initial extraction rate, h, and the absolute temperature.

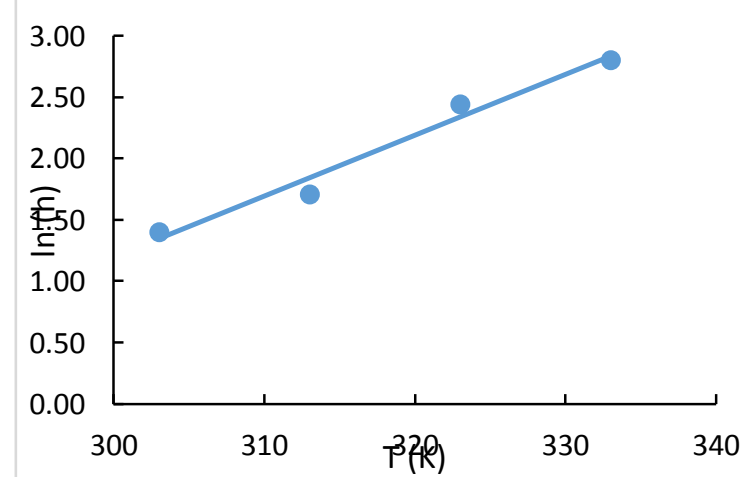

Figure 6: Linear relationship between the initial extraction rate, $\ln (\mathrm{h})$, and temperature.

Figure 7 shows that Cs increased with the extraction temperature with goodness of fitting, $\mathrm{R}^{2}$ of 0.956 (based on Equation 16). The increment of temperature will cause greater disruption to the cell wall and membrane that facilitates faster release and dissolution of anthocyanins from the $\mathrm{G}$. crepioides leaves into the solvent.

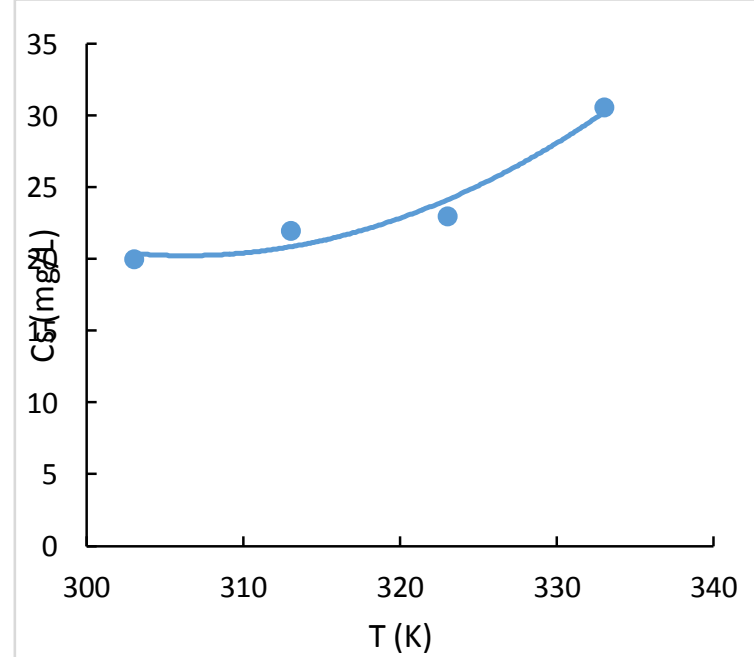

Figure 7: Variation of the saturated extraction capacity, Cs against extraction temperature.
The rate law for a second-order reaction and the relationship of $\mathrm{Ct}$, $\mathrm{T}$ and $\mathrm{t}$ can be expressed by substituting equation (14) and equation (15) into equation (10) as follows:

$\mathrm{C}_{\mathrm{ACs}, \mathrm{t}}=\frac{\left(0.0228 \mathrm{~T}^{2}-14.9239 \mathrm{~T}+2459.41\right) \mathrm{t}}{1+\mathrm{t}}$

Equation (16) is the empirical equation that represents the predictive model for the ACs extracted from G. crepioides at any time and temperature. Based on equation (16), more ACs from G. crepioides leaves will be extracted at a higher extraction temperature. This equation is only valid for time between 0-300 minutes and temperatures between $303 \mathrm{~K}$ and $333 \mathrm{~K}$. The three-dimensional plot of equation (16) is shown in Figure 8. The 3-D plot is important for the determination of the highest yield of ACs based on the extraction time and temperature; and this can help to minimize time and solvent used.

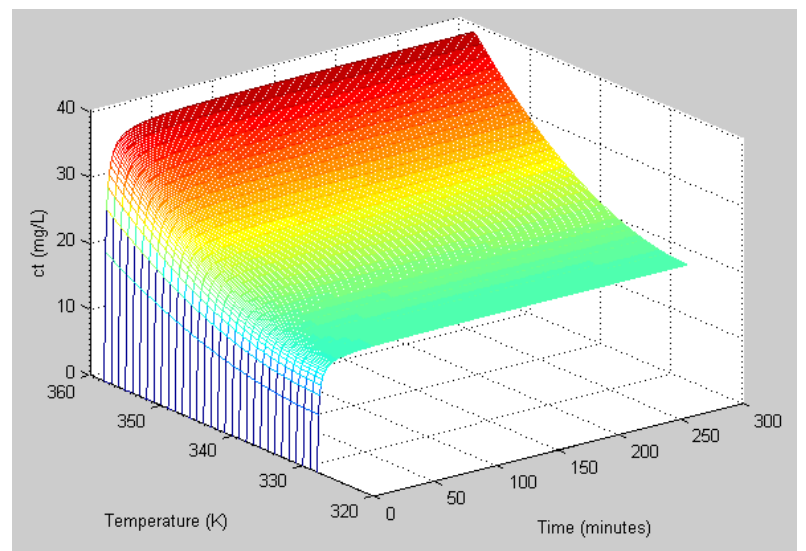

Figure 8: Predictive model for solid-liquid extraction of ACs from $\mathrm{G}$ crepioides leaves at any time and temperatures.

Experimental results of solid-liquid extraction of ACs from the leaves of G. crepioides is compared with the calculated values from equation (17), which originated from the assumption of second-order mechanism of the extraction process. Figure 9 presents a good fitting between the experimental data and calculated data at $323 \mathrm{~K}$ from equation (17) with low standard deviation among the values of between $+/-0.03$ to $+/-3.2$.

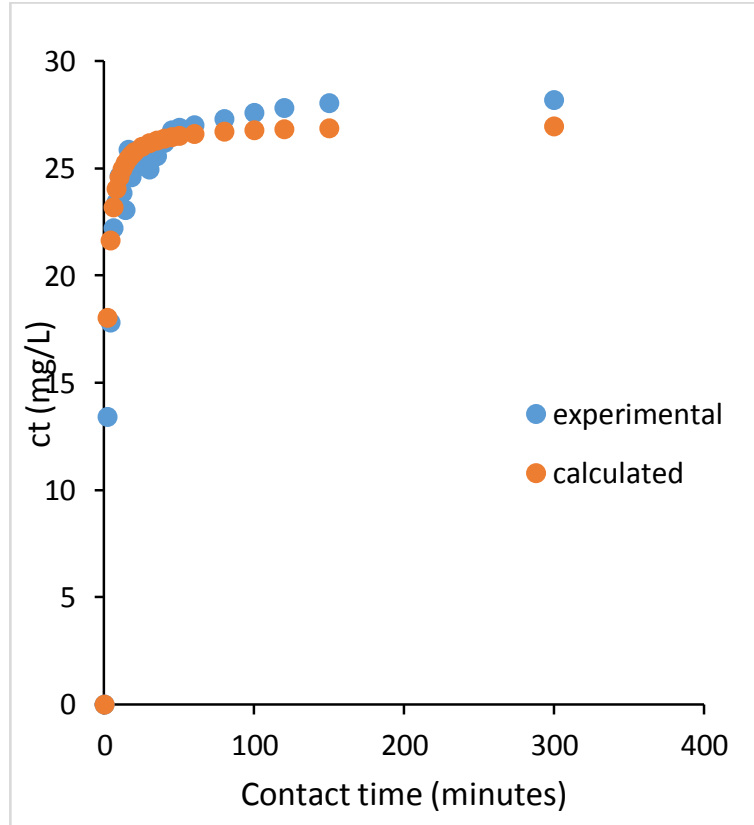

Figure 9: Comparison between experimental and calculated (model) extraction rate of ACs from G. crepioides leaves at $323 \mathrm{~K}$. 


\section{Conclusion}

The kinetics of extraction of ACs from the leaves of $G$. crepioides was studied as a function of temperature and followed a second order extraction that was developed to predict $\mathrm{k}$, Cs and $\mathrm{h}$. The second order $\mathrm{k}$ values were used to evaluate activation energy of extraction was $18.45 \mathrm{~kJ}$ mol-1 of ACs. An empirical correlation was also done to establish the relationship of extraction rate constant, $\mathrm{k}$ and initial extraction rate $(\mathrm{h})$ with respect to temperature. Both parameters were found to increase with increase temperature. Finally, a three-dimensional model was predicted to show the capacity of extraction at all times and temperatures of extraction. This predicted model exhibited good fitting to experimental values with low standard deviation.

\section{Acknowledgement}

Appreciation to MARDI Malaysia, for providing the samples for this research and Universiti Putra Malaysia for providing financial support.

\section{References}

[1] Li, W. L., Ren, B. R., Min-Zhuo et al. (2009). The antihyperglycemic effects of plants in Genus Gynura Cass. The American Journal of Chinese medicine, 37: 961-966

[2] Toeh, W. Y., Sim, K. S., Moses Richardson, J. S., Abdul Wahab, N., Hoe, S. Z. (2013). Antioxidant capacity, cytotoxicity, and acute oral toxicity of Gynura bicolor. Evidence-based complementary and alternative medicine: 1-10.

[3] Shimizu, Y., Maeda, K., Kato, M., Shimomura, K. (2010). Mathyl jasmonate induces anthocyanin accumulation in Gynura bicolor cultured roots. In Vitro Cell. Dev. Biol., 46: 460-465.

[4] Zhang, Z. Q., Pang, X. Q., Ji, Z. L. Jiang, Y. M. (2001). Role of anthocyanins degradation in litchi pericarp browning. Food Chemistry, 75: 217-221.

[5] Cisse, M., Vaillant, F., Acosta, O., Dhuique-Mayer, C., Dornier, M (2009). Thermal degradation kinetics of anthocyanins from blood orange, blackberry, and rosella using the Arrhenius, Eyring, and Ball models. Journal of Agricultural and Food Chemistry, 57: 6285 6291.

[6] Rakotondramasy-Rabesiaka, L., Havet J. -L., Porte C., Fauduet, H. (2007). Solid-liquid extraction of protopine from Fumaria officinalis L. -Analysis determination, kinetic reaction and model building. Separation and Purification Technology, 54: 253-261.

[7] Tzima, K., Kallithraka, S., Kotseridis, Y., P. Marris, D. (2014). Ki netic modelling for flavonoid recovery from red grape (Vitis vinifera) pomace with aqueous lactic acid. Processes, 2, 901-911.

[8] Sepidar, S., Zurina, Z. A., and Yunus, R. (2009). Optimisation of solid liquid extraction of jatropha oil using petroleum ether. AsiaPacific Journal of Chemical Engineering, 8(3),331-338. 